\title{
Governing Heat and Mass Transfer Equation for Solid Desiccant Dehumidifier Wheel
}

\author{
Hanumant B. Narute*, C. Shriramshastri and Vivekanand N. \\ Department of Mechanical Engineering (Heat Power), SPPU Pune, Maharashtra, India \\ Accepted 15 June 2016, Available online 20 June 2016, Special Issue-5 (June 2016)
}

\begin{abstract}
Desiccant cooling system (DCS) is an alternate suitable option against conventional cooling system in a hot and humid climate. Solid Desiccants are natural or synthetic substances capable of absorbing moisture present in the outdoor air. Desiccant wheels are rotary desiccant dehumidifiers used in air conditioning for dehumidification applications. The modeling of concurrent heat and mass transfer in these components is crucial for estimating their performances. A steady state one-dimensional model is developing and resolves to obtain good accuracy and short computational times. Experimental data have to be gathered to resolve eventual missing phenomena and validate the model for all input parameters. The modeling result are used to develop simple correlations for the outlet air conditions of humidity and temperature of air through the desiccant wheel as a function of the physically measurable input variables. These correlations will be used to reproduce the solid desiccant wheel in an air conditioning system in order to define the year round efficiency. In solid desiccant system moist air enters the process side and passes over the desiccant and is dehumidify. As a result of decrees in humidity of the process air and increases its temperature. In the other hand, the humidity ratio of the regeneration air is increased and its temperature decreases.
\end{abstract}

Keywords: Solid Desiccant, Dehumidification, Modeling of Desiccant Wheel.

\section{Introduction}

The Reduction of the environmental impact and energy saving are higher once the desiccant material is regenerated by means of "free" thermal energy (Giovanni Angrisani, 2011). The desiccant wheel is that the most vital part for a desiccant dehumidifier. A rotating cylindrical wheel may be a rotary regenerative desiccant wheel divided into two sections: regeneration sections and dehumidification sections. The dehumidification and regeneration air streams are sometimes in a counter-flow arrangement. The desiccant wheel turns slowly to reveal one portion of the desiccant material to the hot regeneration air stream whereas the opposite portion at the same time passes through the wet method air stream. A partition and versatile seals separate the process and regeneration air streams within the dehumidifier.

Hybrid desiccant air-conditioning system, which is combination of a rotary solid desiccant dehumidification and a vapor compression airconditioning unit (C.X. Jia,2006). Solid desiccant wheel works on principle of adsorption. during which the desiccant materials like silica gel is adsorb additional quantity of molecules into pores on their surface. two air streams are passes over the desiccant wheel; one

*Corresponding author: Hanumant B. Narute stream (Process air) loses moisture to the desiccant materials whereas the other (Regeneration air) removes that vapour due to vapour pressure difference. The porous desiccant medium of the matrix is cylindrically operated for adsorption and desorption. In process of the desiccant wheel, dehumidification of air takes place and within the reactivation a part of the wheel humidification of the air takes place. Rotation of the wheel causes periodic reactivation of the adsorption part. Consequently the solid desiccant wheel need source of warmth to dry out the process air throughout adsorption, heat discharged as desiccant adsorbs vapour.

The heat generated within the desiccant is transferred through the material that decreases the sorption capacity. Therefore, the heat and mass transfer inside the solid desiccant are coupled and will be considered commonly in developing mathematical model. The modeling of a desiccant wheel used for dehumidifying the ventilation air of an air-conditioning system, which predicts the temperature and humidity states of the outlet air from a desiccant wheel and the optimum speed of the wheel once used as a dehumidifier ( Fatemeh Esfandiari Nia, 2006). The desiccant material is regenerated by means of heating coil (at temperature of concerning 1100C). The subsequent performance parameters are evaluated: 
-The moisture Removal capacity of the wheel.

-The dehumidification effectiveness.

-The Dehumidification coefficient of Performance.

-The sensible Energy ratio, SER.

Table 1. Nomenclature

\begin{tabular}{|c|c|}
\hline $2 \mathrm{a}$ & Length of flow passage of one channel \\
\hline $2 \mathrm{~b}$ & Pitch of flow passage of one channel \\
\hline$A_{f}$ & Cross sectional area of flow passage of channel. \\
\hline$A_{t}$ & Total Cross sectional area of flow passage. \\
\hline$\Delta$ & Thickness of Channel wall \\
\hline $\mathrm{Dx}$ & Length of control volume \\
\hline $\mathrm{A}_{\mathrm{r}}$ & Area ratio \\
\hline$\varepsilon$ & Porosity in desiccant \\
\hline$V_{\text {pores }}$ & Volume of pores \\
\hline$V_{\text {total }}$ & Desiccant Volume \\
\hline $\mathrm{V}_{\mathrm{d}}$ & Volume of matrix material \\
\hline$V_{\mathrm{m}}$ & Volume ratio of desiccant in layer \\
\hline$\Phi$ & Velocity of the air at the entrance of control \\
\hline $\mathrm{U}$ & volume \\
\hline$\rho_{\mathrm{a}}$ & Combity of air at entrance \\
\hline $\mathrm{D}_{\mathrm{comb}}$ &
\end{tabular}

\section{Mathematical Modeling}

A Rotary regenerative solid desiccant wheel, cross section of sinusoidal channel and control volume in model as shown in the following fig. 1 One sinusoidal channel with length ' $d x$ '. Where cross sectional area of flow passage ' $A_{f}$ ', Perimeter of air flow passage of one channel ' $\mathrm{P}_{\mathrm{e}}$ ' and total cross sectional area of one channel ' $A_{t}$ '.

2.1 For the simplicity following assumption has been considered:

(1) All air channels assumed to be adiabatic.

(2) Axial heat conduction and mass diffusion in the moisture are neglected.

(3) The thermodynamic properties in the solid desiccant, dry air and matrix material are constant.

(4) Rotary speed is constant and low enough to neglect the effect of centrifugal forces.

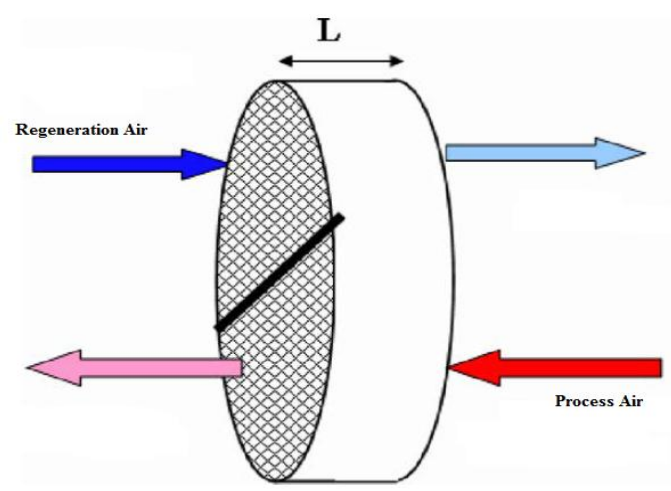

(a)

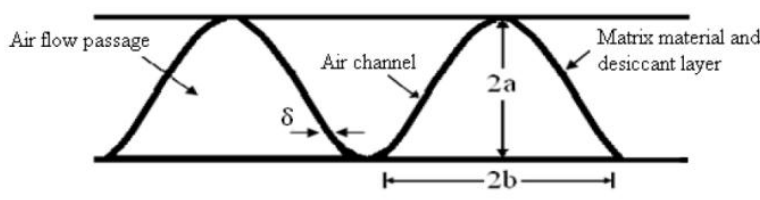

(b)

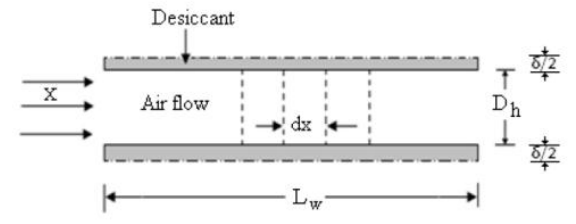

(c)

Fig.1 Schematic Diagram of (a) Desiccant Wheel (Fatemeh Esfandiari Nia, et.al. 2006), (b) cross section of channels (c) differential control volume.

\subsection{Governing Equation}

Cross sectional area of flow passage of one channel $\mathrm{A}_{\mathrm{f}}=\frac{1}{2}(2 \mathrm{a})(2 \mathrm{~b})=2 \mathrm{ab}$

Total cross sectional area of flow passage of one channel $\left(A_{t}\right)=\frac{1}{2}(2 a+\delta)(2 b+\delta)$

The perimeter and hydraulic diameter is given by (Zhang at al, 2013)

Perimeter of flow passage of one channel

$=P_{e} \approx 2 \mathrm{~b}+2 \sqrt{b^{2}+(a \pi)^{2}} \frac{3+\left(\frac{2 b}{a \pi}\right)^{2}}{4+\left(\frac{2 b}{a \pi}\right)^{2}}$

Hydraulic diameter of flow passage of one channel

$=\mathrm{D}_{\mathrm{h}}=4 \frac{\mathrm{A}_{\mathrm{f}}}{P_{e}}$

Area ratio $=\mathrm{A}_{\mathrm{r}}=\frac{\mathrm{A}_{\mathrm{f}}}{A_{t}}$

Porosity in desiccant $=\varepsilon=\frac{V_{\text {pores }}}{V_{\text {total }}}$

$\mathrm{V}_{\text {total }}=\mathrm{V}_{\text {pores }}+\mathrm{V}_{\mathrm{d}}+\mathrm{V}_{\mathrm{m}}$

Volume ratio in desiccant $=\varphi=\frac{V_{d}}{V_{d}+V_{m}}$

Cross sectional area of layer (desiccant + pores + matrix material) of one channel

$A_{\text {layer }}=\left(1-A_{r}\right) A_{t}$

Cross sectional area of pores in layer of one channel

$=A_{\text {pores }}=\varepsilon\left(1-A_{r}\right) A_{t}$

Cross sectional area of layer without pores (desiccant + pores + matrix material) of one channel

$=(1-\varepsilon)\left(1-A_{r}\right) A_{t}$

Cross sectional area of desiccant in layer of one channel

A d $=(1-\varepsilon)\left(1-A_{r}\right) A_{t} \varphi$

Cross sectional area of matrix material in layer of one channel

A $m=(1-\varepsilon)\left(1-A_{r}\right) A_{t}(1-\varphi)$

a) Mass Conservation in control volume of air Rate of accumulation of mass in control volume $\frac{\partial m_{a}}{\partial t}=\frac{\partial}{\partial t}\left(\rho_{\mathrm{a}} \times\right.$ control volume $)$

Inflow $=m_{\mathrm{x}}=\rho_{\mathrm{a}} \mathrm{A}_{\mathrm{r}} \mathrm{A}_{\mathrm{t}} \mathrm{u}$

Outflow $=m_{x}+\frac{\partial}{\partial t}\left(\dot{m}_{\mathrm{a}}\right) \mathrm{dx}+\mathrm{h}_{\mathrm{m}} \mathrm{P}_{\mathrm{e}} \mathrm{dx}\left(\omega_{\mathrm{a}}-\omega_{\mathrm{d}}\right)$

Rate of accumulation of mass in control volume 
= inflow - outflow

The mass conservation in air can be expressed as

$\rho_{\mathrm{a}} A_{t} A_{r}\left(\frac{\partial \omega_{a}}{\partial t}+u \frac{\partial \omega_{d}}{\partial t}\right)=h_{m} P\left(\omega_{a}-\omega_{d}\right)$

b) Mass Conservation in control volume of Desiccant In desiccant layer moisture will be absorbed by desiccant surface and trapped in pores of desiccant Rate of accumulation of mass in control volume

$=$ Rate of accumulation of air in pores + Rate of accumulation of water on desiccant surface

$$
\begin{aligned}
& =\left[\frac{\partial \mathrm{m}_{\mathrm{a}}}{\partial \mathrm{t}}\right]_{\text {pores }}+\left[\frac{\partial \mathrm{m}_{\text {desiccant+water }}}{\partial \mathrm{t}}\right]_{\text {Desiccant }} \\
& =\varepsilon\left(1-\mathrm{A}_{\mathrm{r}}\right) \mathrm{A}_{\mathrm{t}} \mathrm{dx} \rho_{\mathrm{da}} \frac{\partial \omega_{\mathrm{d}}}{\partial \mathrm{t}}+(1-\varepsilon)\left(1-\mathrm{A}_{\mathrm{r}}\right) \mathrm{A}_{\mathrm{t}} \varphi \mathrm{dx} \rho_{\mathrm{a}} \frac{\partial \mathrm{W}}{\partial \mathrm{t}}
\end{aligned}
$$

The diffusion takes place by mechanisms

1) Surface diffusion inflow:-

$\dot{\mathrm{N}}_{\mathrm{x} \text { (surface diffusion })}=-\mathrm{D}_{\mathrm{s}} \frac{\partial}{\partial \mathrm{x}}\left(\rho_{\mathrm{a}}-\rho_{\mathrm{d}}\right)_{\text {desiccant }} \times$ Area of desiccant

\section{Outflow:-}

$\dot{\mathrm{N}}_{(\mathrm{x}+\mathrm{dx}) \text { (surface diffusion) }}=\dot{\mathrm{N}}_{\mathrm{x}(\text { surface diffusion })}+\frac{\partial}{\partial \mathrm{x}}\left[\dot{\mathrm{N}}_{\mathrm{x}(\text { surface }}\right.$ diffusion)] dx

2) Ordinary and knudsen diffusion of air in pores

$\dot{\mathrm{N}}_{\mathrm{x}(\text { comb diffusion })}=-\mathrm{D}_{\text {comb }} \frac{\partial}{\partial \mathrm{x}}\left(\rho_{\mathrm{da}}-\rho_{\mathrm{v}}\right)_{\text {pores }} \times$ Area of pores Outflow:-

$\dot{\mathrm{N}}_{(\mathrm{x}+\mathrm{dx})(\text { (Comb diffusion) }}=\dot{\mathrm{N}}_{\mathrm{x}(\text { comb diffusion })}+$

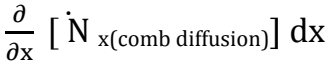

Rate of mass inflow due to convective mass transfer

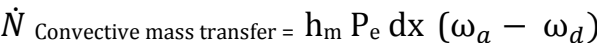

Rate of accumulation of mass in control volume =inflow - outflow

$=\left[\dot{\mathrm{N}}_{\mathrm{x} \text { (surface diffusion })}+\dot{\mathrm{N}}_{\mathrm{x} \text { (comb diffusion) }}+\dot{\mathrm{N}}_{\text {convective mass transfer }}\right]$

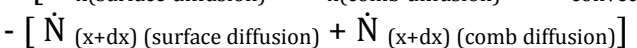

$=\rho_{\mathrm{d}} \mathrm{A}_{\mathrm{d}} \mathrm{D}_{\mathrm{s}} \frac{\partial}{\partial \mathrm{x}}\left[\frac{\partial}{\partial \mathrm{x}}\left(\frac{\rho_{\mathrm{w}}}{\rho_{\mathrm{d}}}\right)\right] \mathrm{dx}+\rho_{\mathrm{da}} \mathrm{A}_{\text {pores }} \mathrm{D}_{\mathrm{comb}} \frac{\partial}{\partial \mathrm{x}}\left[\frac{\partial}{\partial \mathrm{x}}\left(\frac{\rho_{\mathrm{v}}}{\rho_{\mathrm{da}}}\right)\right] \mathrm{dx}$

$+h_{m} P_{e} d x\left(\omega_{a}-\omega_{d}\right)$

Rate of accumulation of mass in control volume of desiccant $=$ inflow - Outflow

$\left.\varepsilon\left(1-A_{r}\right) A_{t} \rho_{d a} \frac{\partial \omega_{d}}{\partial t}+(1-\varepsilon)\left(1-A_{r}\right) A_{t} \varphi \rho_{a} \frac{\partial W}{\partial t}=\rho_{d}(1-\varepsilon)\right)(1-$

$\left.A_{r}\right) A_{t} \varphi D_{s} \frac{\partial^{2} W}{\partial t^{2}}+\rho_{d a} \varepsilon\left(1-A_{r}\right) A_{t} D_{c o m b} \frac{\partial^{2} \omega_{d}}{\partial x^{2}}+h_{m} P_{e}$ $\left(\omega_{\mathrm{a}}-\omega_{\mathrm{d}}\right)$

c) Energy conservation on control volume of air Rate of change of stored energy in control volume $\dot{\mathrm{q}}$ Storage $=\left(\rho_{\mathrm{a}} \mathrm{A}_{\mathrm{t}} \mathrm{A}_{\mathrm{r}} \mathrm{dx}\right) \mathrm{c}_{\mathrm{pa}} \frac{\partial \mathrm{T}_{\mathrm{a}}}{\partial \mathrm{t}}$

Rate of flow energy due to advection

$\dot{\mathrm{Q}}_{\mathrm{adv}(\mathrm{x})}=\left(\rho_{\mathrm{a}} \mathrm{A}_{\mathrm{t}} \mathrm{A}_{\mathrm{r}} \mathrm{u}\right) \mathrm{e}$

Where $\mathrm{e}=\mathrm{c}_{\mathrm{pa}} \frac{\partial \mathrm{T}_{\mathrm{a}}}{\partial \mathrm{t}}$

Outflow

$\dot{\mathrm{Q}}_{\mathrm{adv}(\mathrm{x}+\mathrm{dx})}=\dot{\mathrm{Q}}_{\mathrm{adv}(\mathrm{x})}+\frac{\partial}{\partial \mathrm{x}}\left[\dot{\mathrm{Q}}_{\mathrm{adv}(\mathrm{x})}\right] \mathrm{dx}$

Rate of energy Transfer due to convection
$\dot{Q}$ Convective heat transfer $=\mathrm{h} \mathrm{P}_{\mathrm{e}} \mathrm{dx}\left(\mathrm{T}_{a}-\mathrm{T}_{d}\right)$

Rate of energy Transfer due to convection mass transfer

$\dot{Q}$ Convective mass transfer $=\mathrm{h}_{\mathrm{m}} \mathrm{P}_{\mathrm{e}} \mathrm{dx}\left(\omega_{\mathrm{a}}-\omega_{\mathrm{d}}\right) \mathrm{c}_{\mathrm{pv}}\left(\mathrm{T}_{\mathrm{a}}-\mathrm{T}_{\mathrm{d}}\right)$

Rate of change of stored energy in control volume = inflow - outflow

$\rho_{\text {da }}\left(\mathrm{c}_{\mathrm{pda}}+\omega_{a} \mathrm{c}_{\mathrm{pv}}\right)\left(\mathrm{A}_{\mathrm{t}} \mathrm{A}_{\mathrm{r}}\right)\left(\frac{\partial T_{a}}{\partial t}+\frac{\partial T_{d}}{\partial t}\right)=\mathrm{h} \mathrm{P}_{\mathrm{e}} \mathrm{dx}$ $\left(\mathrm{T}_{a}-\mathrm{T}_{d}\right)-\mathrm{h}_{\mathrm{m}} \mathrm{P}_{\mathrm{e}} \mathrm{dx}\left(\omega_{a}-\omega_{d}\right) \mathrm{nc}_{\mathrm{pv}}\left(\mathrm{T}_{a}-\mathrm{T}_{d}\right)$

d) Energy conservation in control volume of desiccant

Rate of change of stored energy $=\left(\rho_{\mathrm{a}} \mathrm{dx} \mathrm{c}_{\mathrm{d}} \mathrm{Ad}\right)\left(\frac{\partial T_{d}}{\partial t}\right)+$ $\left(\rho_{\mathrm{m}} \mathrm{dx} \mathrm{c}_{\mathrm{m}} \mathrm{A}_{\mathrm{m}}\right)\left(\frac{\partial T_{d}}{\partial t}\right)$

Rate of energy transfer due to conduction Inflow:-

$\dot{q}_{\text {conduction }}=\left(-\mathrm{k}_{\mathrm{d}} \mathrm{A}_{\mathrm{d}}\right)\left(\frac{\partial T_{d}}{\partial x}\right)$

Outflow:-

$q_{(\mathrm{x}+\mathrm{dx})(\text { conduction })}=\dot{Q}(\mathrm{x})($ conduction $)+\frac{\partial}{\partial x}\left[\dot{Q}_{(\mathrm{x})(\text { conduction })}\right] \mathrm{dx}$ Rate of energy transfer due to convection $q$ convective heat transfer $=\mathrm{h} \mathrm{P}_{\mathrm{e}} \mathrm{dx}\left(\mathrm{T}_{a}-\mathrm{T}_{d}\right)$

Rate of energy Transfer due to convection mass transfer

$\dot{q}$ convective mass transfer $=\mathrm{h}_{\mathrm{m}} \mathrm{P}_{\mathrm{e}} \mathrm{dx}\left(\omega_{a}-\omega_{d}\right) \mathrm{c}_{\mathrm{pv}}\left(\mathrm{T}_{a}-\mathrm{T}_{d}\right)$

Rate of energy transfer due to Heat of adsorption

$\dot{q}$ adsorption $=\mathrm{h}_{\mathrm{m}} \mathrm{P}_{\mathrm{e}} \mathrm{dx}\left(\omega_{a}-\omega_{d}\right) \mathrm{h}$ ads

The energy conservation $n$ desiccant is given by $\rho_{\mathrm{m}} \mathrm{C}_{\mathrm{m}}(1-\varepsilon)\left(1-\mathrm{A}_{\mathrm{r}}\right) \mathrm{A}_{\mathrm{t}}(1-\varphi) \frac{\partial T_{d}}{\partial t}+\rho_{\mathrm{d}} \mathrm{C}_{\mathrm{d}}(1-\varepsilon)\left(1-\mathrm{A}_{\mathrm{r}}\right) \mathrm{A}_{\mathrm{t}}(1-$ $\varphi)\left[\frac{\partial T_{d}}{\partial t}+\frac{k_{d}}{\rho_{d} c_{d}} \frac{\partial^{2} T_{d}}{\partial x^{2}}\right]=\mathrm{h} \mathrm{P}_{\mathrm{e}} \mathrm{dx}\left(\mathrm{T}_{a}-\mathrm{T}_{d}\right)+\mathrm{h}_{\mathrm{m}} \mathrm{P}_{\mathrm{e}} \mathrm{dx}$ $\left(\omega_{a}-\omega_{d}\right) \mathrm{c}_{\mathrm{pv}}\left(\mathrm{T}_{a}-\mathrm{T}_{d}\right)+\mathrm{h}_{\mathrm{m}} \mathrm{P}_{\mathrm{e}} \mathrm{dx}\left(\omega_{a}-\omega_{d}\right) \mathrm{h}_{\mathrm{ads}--\cdot(4)}$

\subsection{Performance Parameter}

In order to experimentally evaluate the performance of the desiccant wheel as a function of the outdoor air temperature (tout $=\mathrm{t} 1$ ) and humidity ratio $\left(\omega_{1}\right)$, the regeneration temperature $\left(t_{r e g}\right)$ and the ratio between the regeneration and process air Volumetric flow rates, the performance parameters here in described have been analyzed.

(1) The dehumidification effectiveness represents the ratio between the real dehumidification capability and the ideal dehumidification capability of the desiccant wheel (Mandegari MA et.al, 2009).

$\eta_{\text {deh. }}=\frac{\omega_{\mathrm{a}}-\omega_{\mathrm{d}}}{\omega_{\mathrm{d}}}$

(2) The Moisture Removal Capacity, MRC, represents the mass flow rate of moisture removed by the wheel (Slayzak SJ et.al, 2000).

$\operatorname{MRC}=\rho_{1} \mathrm{v}_{\text {proc }}\left(\omega_{a}-\omega_{d}\right)$ 
(3) The Dehumidification Coefficient Of Performance, DCOP is the ratio between the thermal power related to the air dehumidification and the thermal power supplied for the regeneration process (Ge TS et.al, 2010).

$\operatorname{DCOP}=\frac{\rho_{1} \mathrm{v}_{\mathrm{proc}} \Delta \mathrm{h}_{\mathrm{vs}}\left(\omega_{a}-\omega_{d}\right)}{\rho_{1} \mathrm{v}_{\mathrm{reg}}\left(\mathrm{h}_{a}-\mathrm{h}_{d}\right)}$

The latent heat of vaporization of water, has been evaluated by means of the following empirical cubic function (Rogers RR et.al, 2000).

$\Delta \mathrm{h}_{\mathrm{vs}}=-0.614342 \times 10^{-4} \mathrm{t}_{1}{ }^{3}+0.158927 \times 10^{-2} \mathrm{t}_{1}{ }^{2}$ $-0.236418 \times 10 t_{1}+0.250079 \times 10^{4}$

(4) The Sensible Energy Ratio, SER, represents the ratio between the thermal power related to the air heating through the wheel on the process side and the thermal power supplied for the regeneration process (Enteria N et.al, 2009)

$\operatorname{SER}=\frac{\rho_{1} \mathrm{v}_{\text {proc }} \mathrm{C}_{\mathrm{p}}\left(\mathrm{T}_{2}-\mathrm{T}_{1}\right)}{\rho_{1} \mathrm{~V}_{\text {reg }} \mathrm{C}_{\mathrm{p}}\left(\mathrm{T}_{4}-\mathrm{T}_{1}\right)}$

\section{Solution method and Result}

The governing equation are solve by using the simple forward finite difference Numerical solution method and applying boundary condition. The outside air enters the wheel from one end $x=0$. The building exhaust air enters it from the other end $x=L$. In this design parameters of the desiccant wheel given in Table 2 are varying for a fixed range of operating parameters given in Table 3 Optimization of the design parameters has been done to improve the performance of the desiccant wheel.

Table 2: Operating and structural parameters for optimization of design parameters

\begin{tabular}{|c|c|}
\hline Parameters & $\begin{array}{l}\text { Fixed } \\
\text { value }\end{array}$ \\
\hline Rotational speed, N (rph) & 20 \\
\hline Sector angle of process air, $\theta p$ & $180^{0}$ \\
\hline Sector angle of regeneration air, $\theta \mathrm{r}$ & $180^{0}$ \\
\hline Inlet temperature of process air, $\mathrm{Tp}$, in $\left({ }^{\circ} \mathrm{C}\right)$ & $40^{0}$ \\
\hline $\begin{array}{l}\text { Inlet temperature of regeneration air, } \mathrm{Tr} \text {, in ( } \\
\left.{ }^{\circ} \mathrm{C}\right)\end{array}$ & $100^{0}$ \\
\hline $\begin{array}{l}\text { Inlet humidity ratio of process air, Yp,in ( } \\
\text { kgwater vapour / kgdry air) }\end{array}$ & 0.020 \\
\hline $\begin{array}{l}\text { Inlet humidity ratio of regeneration air, Yr,in } \\
\text { (kgwater vapour / kgdry air) }\end{array}$ & 0.020 \\
\hline Velocity of process air, $u_{p}$, in (m/s) & 2 \\
\hline Velocity of regeneration air, $\mathrm{u}_{\mathrm{r}}$, in $(\mathrm{m} / \mathrm{s})$ & 2 \\
\hline
\end{tabular}

Table 3 Design parameter of solid desiccant wheel

\begin{tabular}{|c|c|}
\hline Parameters & Value \\
\hline Wheel length (m) & 0.3 \\
\hline Pitch of flow passage of one channel, 2b (m) & 0.004 \\
\hline
\end{tabular}

\begin{tabular}{|c|c|}
\hline Height of flow passage of one channel, 2a $(\mathrm{m})$ & 0.002 \\
\hline Porosity & 0.4 \\
\hline Volume ratio of desiccant $\Phi$ & 0.7 \\
\hline Aspect ratio of channel & 0.5 \\
\hline The area ratio $\mathrm{Ar}_{\mathrm{r}}$ & 0.8 \\
\hline Area ratio, $\mathrm{A}_{\mathrm{r}} / \mathrm{A}_{\mathrm{p}}$ & $1 / 1$ \\
\hline
\end{tabular}

\section{Conclusion}

A one-dimensional transient model was given in this paper for a solid desiccant wheel. First, some assumptions were created to simplify the governing equations. Then, the governing equations of heat and mass transfer within the control volumes of the process air and the desiccant felt are given. This equation predicts the temperature and humidity states of the outlet air from a desiccant wheel and the optimum speed of the wheel when used as a dehumidifier. Solving these four governing equation by finite difference method further modeling of desiccant wheel is possible. The solid desiccant wheel performs well in a climate with moderate temperature. At higher humidity ratio, the solid desiccant wheel will get higher moisture removal and better DCOP.

\section{References}

Mandegari MA, Pahlavanzadeh H. (2009), Introduction of a new definition for effectiveness of desiccant wheels, Energy, 34, 797-803.

Ge TS, Ziegler F, Wang RZ.(2010), A mathematical model for predicting the performance of a compound desiccant wheel (a model of compound desiccant wheel), Appl Thermal Eng., 30, 1005-15.

Enteria N, Yoshino H, Mochida A, Takaki R, Satake A, Yoshie R, et al.(2009), Construction and initial operation of the combined solar thermal and electric desiccant cooling system. Sol Energy, 83, 130011.

Slayzak SJ, Ryan JP. (2000), Desiccant dehumidification wheel test guide NREL/TP-550-26131.

Jae Dong Chung, (2008), Optimization of desiccant wheel speed and area ratio of regeneration to dehumidification as a function of regeneration temperature, Solar Energy, 83, 625-635.

C.X. Jia, Y.J. Dai, J.Y. Wu, R.Z. Wang, (2006), Analysis on a hybrid desiccant air-conditioning system, Applied Thermal Engineering 26 pp. (23932400).

Giovanni Angrisani, Francesco Minichiello, Carlo Roselli, Maurizio Sasso, (2011), Experimental analysis on the dehumidification and thermal performance of a desiccant wheel, Applied Energy 92, pp. 563-572.

T.S. Ge, Y. Li, R.Z. Wang, Y.J. Dai, (2008), Experimental study on a twostage rotary desiccant cooling system, Energy 33, pp. 1807-1815.

Sanjeev Jaina, P.L. Dhara, S.C. Kaushik, (1999), Experimental studies on the dehumidifier and regenerator of a liquid desiccant cooling system, Applied Thermal Engineering, 20, PP. 253-267.

Jae Dong Chung, Dae-Young Lee, Seok Mann Yoon, (2008), Optimization of desiccant wheel speed and area ratio of regeneration to dehumidification as a function of regeneration temperature, Solar Energy 83 PP. 625-635

X.J. Zhang, Y.J. Dai, R.Z. Wang, (2003), A simulation study of heat and mass transfer in a honeycombed rotary desiccant dehumidifier, Applied Thermal Engineering 23, PP. 989-1003.

D. Pietruschka, U. Eicker, M. Huber, J. Schumacher, (2006), Experimental performance analysis and modelling of liquid desiccant cooling systems for air conditioning in residential buildings, International Journal of Refrigeration 29 PP. 110-124.

T. S. Ge, Y. Li, R. Z. Wang, Y.J. Dai, (2008), Experimental study on a twostage rotary desiccant cooling system, International Journal of Refrigeration, PP. 498-508.

Jongsoo Jeong, Seiichi Yamaguchi, Kiyoshi Saito, Sunao Kawai, (2011),Performance analysis of desiccant dehumidification systems driven by low-grade heat source, International Journal of Refrigeration, PP. 928-945.

G. Panaras a, E. Mathioulakis, V. Belessiotis, N. Kyriakis, (2010), Theoretical and experimental investigation of the performance of a desiccant air-conditioning system", Renewable Energy 35, 1368-1375

Fatemeh Esfandiari Nia et.al. (2006), Modeling and simulation of desiccant wheel for air conditioning, Energy and Buildings, 38, 12301239. 